\title{
PREVALENCE OF REFRACTIVE ERROR AND OTHER OCULAR MORBIDITIES AND FOLLOW-UP STUDY ON COMPLIANCE TO SPECTACLES USE AMONG SCHOOL GOING CHILDREN AGED 9-16 YEARS IN SELECTED VILLAGE OF HASSAN
}

\author{
Sumana $M^{1}$, Sreelatha C. $Y^{2}$, Krishna Sagar ${ }^{3}$, Kruthi $^{4}$, Anjan Sreeranga ${ }^{5}$ \\ ${ }^{1}$ Assistant Professor, Department of Community Medicine, Hassan Institute of Medical Sciences, Hassan. \\ ${ }^{2}$ Assistant Professor, Department of Community Medicine, Hassan Institute of Medical Sciences, Hassan. \\ ${ }^{3}$ Intern, Department of Community Medicine, Hassan Institute of Medical Sciences, Hassan. \\ ${ }^{4}$ Intern, Department of Community Medicine, Hassan Institute of Medical Sciences, Hassan. \\ ${ }^{5}$ Tutor, Department of Community Medicine, Hassan Institute of Medical Sciences, Hassan.
}

\begin{tabular}{l}
\hline ABSTRACT \\
BACKGROUND \\
Uncorrected refractive errors are the most common cause of visual impairment in school children in India. \\
AIMS AND OBJECTIVES \\
To find out prevalence and risk factors of refractive error. To identify other ocular morbidities and to assess the compliance to \\
spectacle use.
\end{tabular}

\section{SETTINGS AND DESIGN}

A cross-sectional study was carried out in school going children of age group 9-16 yrs. in Salagame, Hassan.

\section{METHODS AND MATERIALS}

All school going children were examined using Snellen's chart at $6 \mathrm{~m}$ distance, height and weight are measured using appropriate scale, external appearance of eyes examined using torch, colour vision examined by Ishihara chart. Refractive error, parental refractive error, close reading and TV watching, sociodemographic profile etc., were assessed in all children by sending questionnaire to parents. After six months, school was revisited without prior notice to assess how many were actually wearing spectacles.

\section{STATISTICAL ANALYSIS USED}

Statistical analysis was done using Microsoft Excel for data entry and Epi Info software for analysis. Descriptive statistics to summarize and Chi square test to correlate risk factors and refractive error.

\section{RESULTS}

Among 362 students examined, 179 were boys and 183 were girls. Prevalence of refractive error was 8.3\%. Age, Close TV watching and parental use of spectacles were found to be significant in the prevalence of refractive error in school going children. Only $38 \%$ children were wearing spectacles at the time of followup.

\section{CONCLUSION}

There is the need for periodic screening and followup of students studying in Government schools. History of close TV watching by parents is an important clue for the presence of refractive errors.

\section{KEYWORDS}

Cross-sectional Studies, Prevalence, Refractive Error, Myopia, School children, Hassan.

HOW TO CITE THIS ARTICLE: Sumana M, Sreelatha C. Y, Krishna Sagar, Kruthi, Anjan Sreeranga. "Prevalence of Refractive Error and other Ocular Morbidities and follow up study on Compliance to Spectacles use among School Going Children Aged 9-16 Years in Selected Village of Hassan." Journal of Evolution of Medical and Dental Sciences 2015; Vol. 4, Issue 96, November 30;

Page: 16163-16166, DOI: $10.14260 /$ jemds/2015/2372

\section{INTRODUCTION}

Uncorrected refractive error is a significant cause of visual impairment in children as suggested by WHO. ${ }^{1}$ Refractive error has been the main cause of visual impairment in children aged between 7 and 15 years in rural India.

Financial or Other, Competing Interest: None.

Submission 13-11-2015, Peer Review 14-11-2015,

Acceptance 23-11-2015, Published 28-11-2015.

Corresponding Author:

Dr. Sumana $M$,

Assistant Professor,

Department of Community Medicine,

Hassan Institute of Medical Sciences,

Hassan.

E-mail: sumana_prasad@yahoo.com

DOI:10.14260/jemds/2015/2372
Importance of early detection and treatment of ocular diseases and visual impairment in young children lies in the fact that $30 \%$ of India's population becomes blind before the age of 20 years. The global financial cost of blindness with an onset during childhood has been estimated to be between US \$6000- $\$ 27,000$ million. $^{2}$

It is estimated that there are 1.4 million blind children in the world, two-third of whom live in the developing countries and of all the blind children 2,70,000 live in India. ${ }^{3}$ Refractive error is one of the major avoidable (Preventable and curable) causes of blindness next only to cataract. School going children form an important large target group, which is easy to approach. About $13 \%$ of Indian population is in the age group of 7-15 yrs. and about $20 \%$ of children develop refractive error by the age of 16 years. ${ }^{4}$ 
Most of the time the children do not complain of visual impairments; hence, early screening and prompt intervention becomes essential. Poor vision in childhood affects performance in school and has a negative influence on the future life of the child.

Thus the present study was undertaken with the Objectives 1 . To find out the prevalence of refractive errors and other ocular morbidities among school going children aged 9 to 16 years in Salagame. 2. To identify the risk factors associated with refractive errors. 3 . To know the compliance rate among children to spectacle use after 6 months followup visit to schools.

\section{METHODS}

Our's was a cross-sectional study conducted to determine the frequency of eye problem in schools coming under the rural field practice area of Community Medicine. Selection of schools was done by simple random technique and all the students were examined of that schools who all were present on the day of examination. Three schools namely Malle Malleshwara High Schools, Salagame; Govt. Middle School, Salagame; Dasarakoppalu Middle School were included in this study.

Study Type: A cross-sectional descriptive study.

Study Period: Two months.

Study Population

School going children aged 9-16 years of selected 3 schools and residing in Salagame, Hassan.

\section{Inclusion Criteria}

All school going children aged 9-16 years.

\section{Exclusion Criteria}

Students who remained absent even after two followups,

Any child with congenital eye disease.

Total children in the school: 391.

Total children examined: 362 .

Proforma sent to all the parents of 362 children after briefing.

\section{Pilot Study}

A pilot study was conducted on 20 children on 23-June-2011 in Salagame to pre-test the proforma and screening method. Questionnaire was appropriately modified based upon the response.

\section{Instruments}

Height and weight are measured using appropriate scale.

External appearance of eyes examined using torch.

Visual acuity examined by Snellen's chart at $6 \mathrm{~m}$ distance. Colour vision examined by Ishihara chart.

\section{METHODS OF DATA COLLECTION}

The information regarding age, sex, problems of the eye, vision etc., was recorded on a proforma and the Snellen's chart was used to measure the visual acuity. The colour card and pin holes were also utilized. WHO criteria of visual acuity $<6 / 18$ were taken as visually impaired while $<3 / 60$ was taken as blindness. If uncorrected vision was $<6 / 12$, the child was declared as defective vision. Variables selected for the study were the socioeconomic and demographic factors, height and weight of the child, mid-arm circumference, number of siblings, number of siblings using glasses, parents' use of spectacles, type of eye problem.

A standard examination procedure was used for each study subject. Visual acuity was done through Snellen chart for distance vision and cards for near vision. Children who failed to pin hole correction were referred to District Hospital.
Step 1: Identification of refractive error by Snellen's chart.

Step 2: Distribution of questionnaires to parents.

Step 3: Correction of refractive error by refractionist.

Step 4: Prescription of spectacles.

Step 5: Follow up after 6 months for compliance of spectacle use.

\section{STATISTICAL ANALYSIS}

Statistical Analysis was done using Microsoft Excel for data entry and Epi Info software for analysis. Descriptive statistics to summarize and Chi square test to correlate risk factors and refractive error.

\section{RESULTS}

A total of 391 children from 3 schools were enumerated and $362(92 \%)$ children were examined, out of which $179(49.4 \%)$ were boys and $183(50.6 \%)$ females. The survey included children of aged 9-16 years. The mean age being 12.6 yrs., uniform distribution of students was observed among the schools and class; $41 \%$ had some form of eye symptoms in the form of watering, headache, infections. The proportions of refractive error was $8.3 \%$. The proportion of colour blindness was $2 \%$. Most common type of refractive error in school children of Salagame was myopia. As the age and class of studying advances refractive error prevalence also increased; 362 students were sent home with the proforma to be filled by their parents. After repeated instructions 318(88\%) proformas were completely filled by parents and were available for analysis.

The parental use of spectacles was present in 3.3\%. Higher prevalence of refractive error $(12.1 \%)$ was observed among children who had parental and sibling use of spectacles. Close TV watching and close reading of books was found to be significant in the prevalence of refractive error in school going children.

There was no significant association observed with gender, PEM, (Body mass index), History of LBW, socioeconomic status.

A $68 \%, 12 \%, 8 \%$ of students with refractive error reported mild, moderate and severe effect on studies and sports. Screening at school using Snellen's chart showed prevalence of refractive error $8.3 \%$. After pin hole and testing by refractionist, children were prescribed spectacles. After six months, these children were followed up for compliance by giving an unannounced visit to the school; $38.4 \%$ were actually wearing the spectacles at the time of followup.

\section{DISCUSSION}

In our study, the prevalence rates of eye problems in general and vision problems due to refractive errors in particular, in school children aged 9 to 16 years were found to be $12.4 \%$ and $8.3 \%$ respectively. This finding is more or less comparable with the results of some studies carried out in other parts of Karnataka, India and world.

The prevalence of refractive error in this study population was $8.3 \%$, similar to the prevalence of myopia observed by GVS Murthy et al. in New Delhi (7.4\%). ${ }^{5}$ Kumar et al. in Lucknow (7.4\%). ${ }^{6}$ Pavithra $\mathrm{MB}$ in Bangalore (7.03\%). ${ }^{7}$ Suryachandra et al. in Srikakulam (7.04\%). ${ }^{8}$ and Kalikivayi et al. in Hyderabad (8.6\%). ${ }^{9}$ Similar studies from different parts of the world showed a prevalence of $(8.2 \%)$ in Baltimore (USA). ${ }^{10}(12.8 \%)$ in Shunyi District in China. ${ }^{11}$ $8.9 \%$ in Karachi. ${ }^{12}$

The study showed a higher prevalence as age advances and in higher classes similar to observed in studies conducted by S Matta et al..$^{13}$ Sethi S. ${ }^{4}$ and other studies. ${ }^{14,15}$ 
Refractive errors presents as various signs, symptoms and manifestations. These manifestations also include close TV watching and reading closely, which could be used as initial screening criteria.

Among other ocular morbidities, prevalence of colour blindness was $2.2 \%$; $3.8 \%$ was observed in study Niroula et al. Although, several therapies have been proposed (e.g. electrical eye stimulation, Iodine injections, large doses of vitamins), there are no treatments or surgical procedures to improve the quality of an individual's chromatic vision. ${ }^{16}$

Higher proportion of myopia was observed in children with parental and sibling use of spectacles (12.1\%). Ayub Ali et al. and Saw et al. also have reported that a positive family history of myopia is related to the progression of myopia and refractive error. 14,15

Followup for compliance to spectacle use was assessed after 6 months by unannounced visit to these schools; 38\% students who were prescribed spectacles were actually wearing the spectacles; $57.8 \%$ in the study conducted in Bangalore. ${ }^{17} 29.5 \%$ among the rural secondary school children in Pune. ${ }^{18}$ and $19.5 \%$ compliance from rural Central India. ${ }^{19}$ Time gap and method of determining compliance defer from one study to another, so it is difficult to compare.

Accordingly, based on the findings of the present study the following recommendations are forwarded: 1 . The present study shows that the adolescent age represent high risk group for refractive errors. Most of the children were unaware of their refractive errors. Therefore, screening in schools and pre-schools ages should be carried out periodically. 2. Children in these ages and their parents should be educated about signs and symptoms of refractive error, ocular hygiene. Close TV watching has come as a significant history among children with refractive errors. Close TV watching can be used for initial screening questions to parents. 3. Eye Health Services provided through School Health Programme should be strengthened, which was observed to be poor in study area during the study period.

Limitation of our study were study conducted only in schools; many children in community who do not go to school might be missed. Cycloplegia was not performed in all children with error, so there could be overall underestimation of refractive errors and we were not able to collect further details regarding factors influencing compliance to spectacle use. Further studies recommended should address identification of barriers to refractive error corrections and factors influencing compliance. Studies to show improvement with respect to studies and sports after corrections with spectacles, the results of which can motivate parents to insist children for spectacle use. Community based studies to cover even the school dropout children.

\section{ACKNOWLEDGEMENTS}

We are thankful to Dr. Sundar M, HOD, Department of Community Medicine for providing us opportunity and support throughout the study. We are grateful to the school communities for the necessary arrangements and support they gave us during data collection. Interns, staff of Dept. of Community Medicine and Medical officer Salagame for helping us in the study. Dr. Kavitha C V, HOD, Department of Ophthalmology for advice and guidance. Mr. Ananthaswamy (Refractionist) for assisting us during the study.

\section{REFERENCES}

1. World Health Organization. Elimination of Avoidable Visual Disability Due to Refractive Errors. Geneva: WHO; 2000. Publication no. PBL/00.79.
2. Gupta Y, Sukul RR, Guptha M, Phougat A, Jain R, Varshney A, School eye survey in rural population in UP, India, Nepal J Ophthalmol 2011;3(5):78-79.

3. World Health Organization. Preventing blindness in children: report of WHO/IAPB scientific meeting. Programme for the Prevention of Blindness and Deafness, and International Agency for Prevention of Blindness. Geneva: WHO, 2000.

4. Sethi S, Kartha GP. Prevalence of refractive errors among school children (12-17 years) of Ahmedabad city. Ind Journal of Com Med. 2000;25:181-83.

5. GVS Murthy, Sanjeev K Guptha, Lcon B, Ellwein, Sergio $\mathrm{R}, \mathrm{Munoz}$, et al., refractive error in children in an urban population in New Delhi, Iovs, March 2002;43:623-630.

6. Kumar JV, Singh PC, Ahuja J, Mohan U. Ocular morbidity among school children in Sarojini Nagar Lucknow. Indian J Community Med. 1992;17:109-113.

7. Pavithra MB, Maheshwaran R, Rani Sujatha MA. A study on the prevalence of refractive errors among school children of 7-15 years age group in the field practice areas of a Medical College in Bangalore. Int J Med Sci Public Health 2013;2:641-645.

8. Suryachandra Mallireddy, Rajkumar Patra. Prevalence of Refractive Errors and Other Ocular Disorders in School Going Children of Srikakulam District Andhra Pradesh. Journal of Evolution of Medical and Dental Sciences 2015; Vol. 4, Issue 53, July 02; Page: 91689172, DOI: $10.14260 /$ jemds/2015/1332.

9. Kalikivayi V, Naduvilath TJ, Bansal AK, Dandona L. Visual impairment in school children in Southern India. Indian J Ophthalmol 1997;45:129-34.

10. Proslan M, Novak C. The Baltimore vision screening project. Trop Med Int Health. 1996:314-319. 12.

11. Zhao J, Pan X, Sui R et al. Refractive error study in Children: results from Shunyi District, China. American J Ophthalmol. 2000;129:427-35.

12. Haseeb Alam1, M. Irfanullah Siddiqui2, Syed Imtiaz Ahmed Jafri3, Abdul Sattar Khan4, Syed Ishtiaq Ahmed5, Mohammad Jafar6, et al. Prevalence of refractive error in school children of Karachi, J Pak Med Assoc; 322-324.

13. Matta S, Matta P, Gupta V, Dev A. Refractive errors among adolescents attending Ophthalmic OPD. Ind Joun Comm Medicine. 2006-04- 2005-06;31(2).

14. Ali A, Ahmad I, Ayub S. Prevalence of undetected refractive error among school children of Lahore. Biomedica. 2007;23:96-101.

15. Saw SM, Katz J, Schein OD, Chew SJ, Chan TK. Epidemiology of myopia. Epidemiol Rev 1996;18:175-187.

16. Niroula DR, CG Saha. The Incidence of Color Blindness among some school children of Pokhara, Western Nepal. Nepal med Coll J 2010;12(1):48-50.

17. Pavithra MB, Hamsa L, Madhukumar S. Factors associated with spectacle-wear compliance among school children of 7-15 years in South India. Int J Med Public Health 2014;4:146-50.

18. Gogate P, Mukhopadhyaya D, Mahadik A, Naduvilath TJ, Sane S, Shinde A, et al. Spectacle compliance amongst rural secondary school children in Pune district, India. Indian J Ophthalmol 2013;61:8-12.

19. Khandekar R, Sudhan A, Jain BK, Tripathy R, Singh V. Compliance with spectacle wear and determinants in school students in Central India. Asian J Ophthalmol 2008;10:174-7. 


\begin{tabular}{|c|c|c|c|c|c|c|c|}
\hline \multirow{2}{*}{$\begin{array}{c}\text { Studying } \\
\text { Class }\end{array}$} & \multirow{2}{*}{ Age } & \multicolumn{4}{|c|}{ Sex } & \multicolumn{2}{|c|}{ Total } \\
\cline { 3 - 7 } & & \multicolumn{2}{|c|}{ Male } & \multicolumn{2}{|c|}{ Female } & \multicolumn{2}{|c|}{} \\
\cline { 3 - 7 } & No & $\mathbf{\%}$ & No & $\mathbf{\%}$ & no & $\%$ \\
\hline $5-6$ & $9-11$ & 34 & 38.2 & 55 & 61.8 & 89 & 100 \\
\hline $7,8,9$ & $12-14$ & 103 & 47.9 & 112 & 52.1 & 215 & 100 \\
\hline 10 & $15-16$ & 42 & 72.4 & 16 & 27.6 & 58 & 100 \\
\hline Total & $\mathbf{9 - 1 6}$ & $\mathbf{1 7 9}$ & $\mathbf{4 9 . 4}$ & $\mathbf{1 8 3}$ & $\mathbf{5 0 . 6}$ & $\mathbf{3 6 2}$ & $\mathbf{1 0 0}$ \\
\hline \multicolumn{8}{|c|}{$\begin{array}{c}\text { Tables 1: Distribution of Study Subjects } \\
\text { according to Age, Sex and Studying Class }\end{array}$} \\
\hline
\end{tabular}

\begin{tabular}{|c|c|c|}
\hline Visual Acuity & No. & \% \\
\hline $6 / 6 \& 6 / 9$ & 332 & 91.71 \\
\hline $6 / 12$ & 19 & 5.24 \\
\hline $6 / 18$ & 6 & 1.65 \\
\hline $6 / 24$ & 3 & 0.82 \\
\hline $6 / 36$ & 1 & 0.27 \\
\hline CF 3mts & 1 & 0.27 \\
\hline Total & $\mathbf{3 6 2}$ & $\mathbf{1 0 0}$ \\
\hline \multicolumn{3}{|c|}{ Table 2: Visual Acuity of the 362 } \\
Children Screened in Salagame \\
\hline
\end{tabular}

\begin{tabular}{|c|c|c|}
\hline Sl. No & Ocular Morbidities & No. (\%) of Children \\
\hline 1 & Squint & $3(0.8 \%)$ \\
\hline 2. & Occular injury & $2(0.5 \%)$ \\
\hline 3. & Chalazion & $1(0.2 \%)$ \\
\hline 4. & Xerophthalmia & $1(0.2 \%)$ \\
\hline 5. & Colour blindness & $8(2.2 \%)$ \\
\hline \multicolumn{3}{|c|}{ Table 3: Other Occular Morbidities } \\
among the Study Subjects
\end{tabular}

\begin{tabular}{|c|c|c|c|c|c|c|}
\hline \multicolumn{1}{|c|}{ REFRACTIVE ERROR } \\
\hline \multirow{2}{*}{ Class } & Present & \multicolumn{2}{c|}{ Absent } & \multicolumn{2}{c|}{ TOTAL } \\
\cline { 2 - 8 } & No & $\mathbf{\%}$ & No & $\mathbf{\%}$ & No & $\%$ \\
\hline 5 & 2 & 5.6 & 31 & 93.94 & 33 & 100 \\
\hline 6 & 4 & 5.6 & 67 & 94.36 & 71 & 100 \\
\hline 7 & 6 & 6.1 & 101 & 94.39 & 107 & 100 \\
\hline 8 & 4 & 6.1 & 43 & 91.49 & 47 & 100 \\
\hline 9 & 9 & 8.5 & 47 & 83.93 & 56 & 100 \\
\hline 10 & 5 & 10 & 43 & 89.58 & 48 & 100 \\
\hline TOTAL & $\mathbf{3 0}$ & $\mathbf{8 . 2 9}$ & $\mathbf{3 3 2}$ & $\mathbf{9 1 . 7 1}$ & $\mathbf{3 6 2}$ & $\mathbf{1 0 0}$ \\
\hline
\end{tabular}

Chi-square df Probability

$\begin{array}{lll}12.5171 & 5 & 0.0284\end{array}$

\begin{tabular}{|c|c|c|c|}
\hline \multirow{2}{*}{$\begin{array}{l}\text { Close TV } \\
\text { Watching }\end{array}$} & \multicolumn{2}{|c|}{ Refractive Error } & \multirow{2}{*}{ Total } \\
\hline & Present & Absent & \\
\hline Present & $\begin{array}{c}9 \\
(18 \%)\end{array}$ & $\begin{array}{c}41 \\
(82 \%)\end{array}$ & 50 \\
\hline Absent & $\begin{array}{c}15 \\
(6.2 \%)\end{array}$ & $\begin{array}{c}226 \\
(93.8 \%)\end{array}$ & 241 \\
\hline Not ans & $\begin{array}{c}1 \\
(3.7 \%)\end{array}$ & $\begin{array}{c}26 \\
(96.3 \%)\end{array}$ & 27 \\
\hline Total & $\begin{array}{c}25 \\
(7.9 \%)\end{array}$ & $\begin{array}{c}293 \\
(92.1 \%)\end{array}$ & 318 \\
\hline
\end{tabular}

Chi-square df Probability

$\begin{array}{lll}9.9076 & 2 & 0.0071\end{array}$

\begin{tabular}{|c|c|c|c|}
\hline \multicolumn{4}{|c|}{ Refractive Error } \\
\hline Symptoms & Present & Absent & TOTAL \\
\hline Dim. vision & 3 & 1 & 4 \\
Row \% & 75 & 25 & 100.0 \\
\hline Headache & 10 & 103 & 113 \\
Row \% & 8.8 & 91.2 & 100.0 \\
\hline Watering & 1 & 13 & 14 \\
Row \% & 7.1 & 92.9 & 100.0 \\
\hline No symptoms & 11 & 170 & 181 \\
Row \% & 6.1 & 93.9 & 100.0 \\
\hline TOTAL & $\mathbf{2 5}$ & $\mathbf{2 8 7}$ & $\mathbf{3 1 2}$ \\
Row \% & $\mathbf{8 . 0}$ & $\mathbf{9 2 . 0}$ & $\mathbf{1 0 0 . 0}$ \\
\hline \multicolumn{4}{|c|}{ Table 6: Symptoms of Visual } \\
Impairment and Refractive Error \\
\hline
\end{tabular}

\begin{tabular}{|c|c|c|c|}
\hline \multicolumn{5}{|c|}{ Refractive Error } \\
\hline Eff St and Sp & Present & Absent & TOTAL \\
\hline No effects & 17 & 220 & 237 \\
Row \% & 7.2 & 92.8 & 100.0 \\
\hline Mild effect & 3 & 32 & 35 \\
Row \% & 8.6 & 91.4 & 100.0 \\
\hline Severe & 2 & 0 & 2 \\
Row \% & 100.0 & 0.0 & 100.0 \\
\hline Not ans & 3 & 41 & 44 \\
Row \% & 6.81 & 93.18 & 100.0 \\
\hline TOTAL & $\mathbf{2 5}$ & $\mathbf{2 9 3}$ & $\mathbf{3 1 8}$ \\
Row \% & $\mathbf{7 . 9}$ & $\mathbf{9 2 . 1}$ & $\mathbf{1 0 0 . 0}$ \\
\hline \multicolumn{4}{|c|}{ Table 7: Effect of Refractive } \\
\hline \multicolumn{4}{|c|}{ [rror Studies and Sports } \\
\hline
\end{tabular}

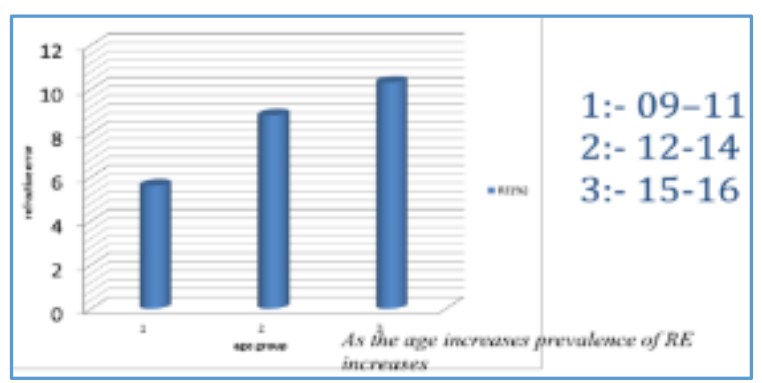

Age Wise Distribution of Refractive Error 